\title{
STUDY ON SINTERING OF ARTIFICIALLY OXIDIZED STEEL COMPACTS
}

\author{
C. Gierl-Mayer, T. Stepan, J. Sun, H. Danninger
}

\begin{abstract}
Sintering of Cr-prealloyed PM steels requires atmospheres with good quality - low oxygen potential - to achieve satisfactory sintering results. But during heating even the best atmospheres may be oxidizing, the system turns to reducing conditions only at high temperatures, which can be monitored by thermal analysis. During the dewaxing process, oxidizing conditions are favourable for effective dewaxing without sooting and blistering. However, this may result in some oxygen pickup during heating, and then the final properties of the produced parts may be strongly influenced by this intermediate oxidation. This study demonstrates the behaviour of artificially oxidized steels ( $\mathrm{Fe}-\mathrm{C}$ and $\mathrm{Fe} 3 \mathrm{Cr}-0.5 \mathrm{Mo}-\mathrm{C}$ ) during the sintering process by stepwise sintering. Iron and steel powder were slightly oxidized and then pressed and sintered at different temperatures. In parallel, as a second approach, pressed samples were oxidized and then sintered. Density, hardness and impact energy were measured and dilatometry/MS was used for online monitoring of the sintering process. The starting oxygen content of 0.20 to $0.30 \mathrm{wt} \%$ is high enough to change the sintering behaviour of the materials, but still leads to rather good properties. Thermal analysis showed that most of the oxygen picked up was present as iron oxides on the surface which were reduced by hydrogen at rather low temperatures, confirming that these were iron oxides, which also holds for the Cr-prealloyed variant. The biggest influence on the final performance was exerted by the final carbon content and the microstructural development of the material.
\end{abstract}

Keywords: sintering behaviour, mechanical properties, oxygen, "Oxidation" reduction, decarburization

\section{INTRODUCTION}

Sintering of Cr-prealloyed PM steels opens new markets in terms of interesting mechanical properties for PM parts, but since chromium is more oxygen sensitive than iron, the requirements for sintering of these materials have changed compared to classical PM steels. In [1-4] it is demonstrated that $\mathrm{Cr}$ prealloyed powders contain an Fe oxides layer on their surface with disperse particulates of complex oxides. Consequently the sintering requires deoxidation at low temperatures by hydrogen to prevent "internal gettering", i.e. oxygen transfer from iron oxides on the surface to the more stable elements [5]. This oxygen transfer should be avoided since once these more stable oxides are formed, higher sintering temperatures are required for reduction, which means that the mechanism is carbothermal reduction.

Christian Gierl-Mayer, Thomas Stepan, Jie Sun, Herbert Danninger: Institute of Chemical Technologies and Analytics, TU Wien. Vienna, Austria. 
The discussion whether it is direct or indirect reduction is still ongoing [6]. The carbothermal reduction influences the final carbon content of the sintered material and therefore the mechanical properties and the dimensional behaviour. But even when the best sintering conditions are applied the dewaxing process has to be kept in mind. Usually the dewaxing is more effective in slightly oxidizing atmospheres to break down the long-chain additives effectively in order to avoid sooting and blistering. However, this treatment may result in oxygen pickup during the initial stages of the sintering run.

In this article it is tried to identify the effects of such intermediate oxidation. It describes the influence of an artificial oxidation on the final properties by stepwise sintering and dilatometric experiments to identify the critical temperature ranges and the sintering mechanisms.

\section{EXPERIMENTAL PROCEDURE}

Plain iron (ASC100.29) and prealloyed Fe-3Cr-0.5Mo (AstaloyCtM) - both from Höganäs $\mathrm{AB}$ - were chosen as test materials. The final mixture was $\mathrm{Fe}-0.5 \mathrm{C}$ and $\mathrm{Fe} 3 \mathrm{Cr}$ $0.5 \mathrm{Mo}-0.5 \mathrm{C}$ whereas carbon was added as graphite (Kropfmühl UF4). The experiments of this study were performed in two steps. The first step was to find conditions for reasonable, but not too pronounced, oxidation of the powder, so $300^{\circ}$ and $400^{\circ} \mathrm{C}$ for 30 and $60 \mathrm{~min}$ were chosen, in all cases in air. For oxidation at $300^{\circ} \mathrm{C}$ a drying chamber was used, and for $400^{\circ} \mathrm{C}$ a tube furnace was purged with air.

The oxidation was performed in two different ways: The first variant was to oxidize the pressed samples, compacted at $600 \mathrm{MPa}$ in a floating die $\left(55 \times 10 \times 10 \mathrm{~mm}^{3}\right.$, charpy bars according to ISO 5754) with die wall lubrication. This method should demonstrate the effects of oxidation which might occur during the debinding or sintering process if the atmosphere is not adequate at low temperatures. The second variant was to oxidize the base ferrous powder (before mixing with graphite) in a steel boat placed in a drying chamber. This variant was chosen to prove the effect of freshly reduced surfaces which are said to be more active in sintering than the standard powder. Originally the oxidation of the powder was planned for $400^{\circ} \mathrm{C}$, too, but analysis of pressed samples showed that oxidation was too severe at $400^{\circ} \mathrm{C}$, so this experiment was skipped (see also LOM and SEM pictures of the broken surfaces in Fig. 1 and 2).

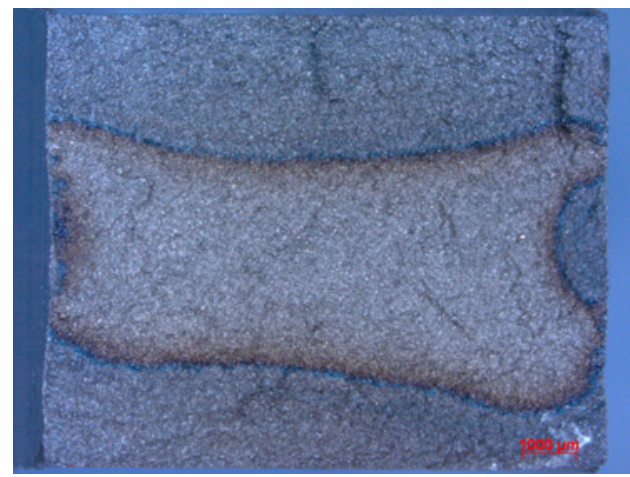

ASC-0.5C

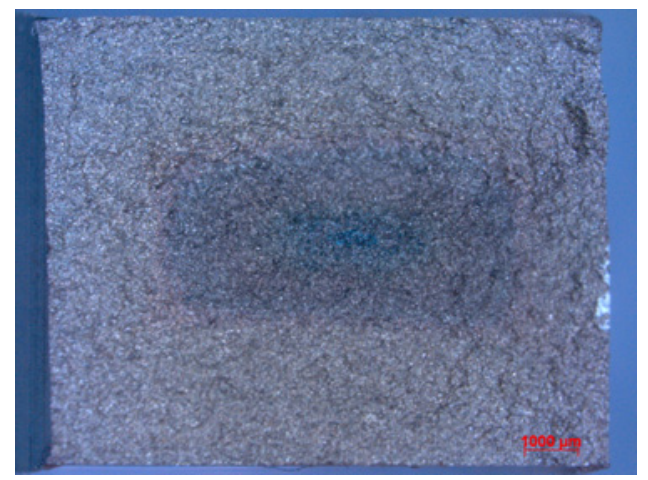

CrM-0.5C

Fig.1. Fracture surfaces of samples after oxidizing treatment at $400^{\circ} \mathrm{C}$ for $60 \mathrm{~min}$ in air; macroscopic images. 


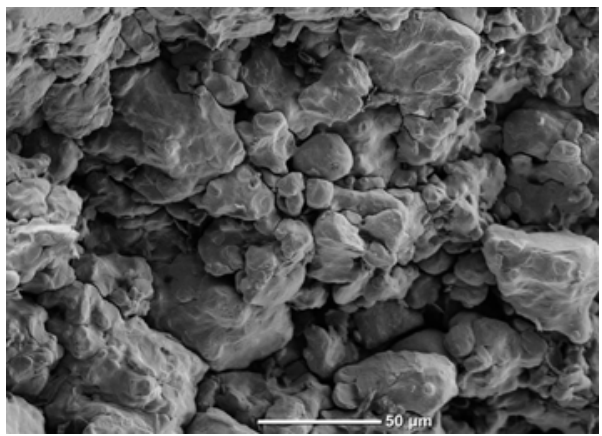

a) $\mathrm{Fe}-0.5 \mathrm{C}$ untreated

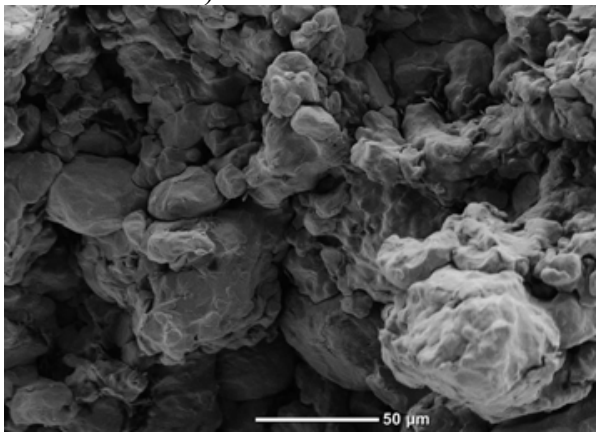

c) $\mathrm{Fe}-3 \mathrm{Cr}-0.5 \mathrm{Mo}-0.5 \mathrm{C}$ untreated

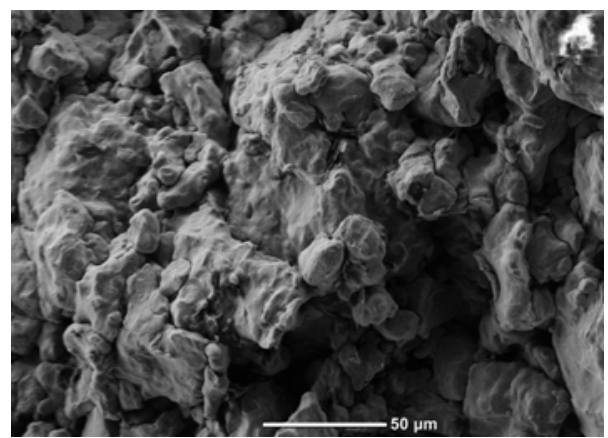

b) $\mathrm{Fe}-0.5 \mathrm{C} 400^{\circ} \mathrm{C} 60 \mathrm{~min}$

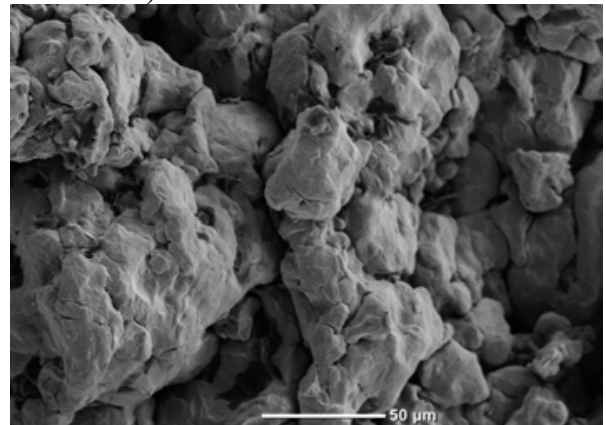

d) $\mathrm{Fe}-3 \mathrm{Cr}-0.5 \mathrm{Mo}-0.5 \mathrm{C} 60 \min 400^{\circ} \mathrm{C}$

Fig.2. Fracture surfaces untreated and after oxidation at $400^{\circ} \mathrm{C}$; SEM images.

Tab.1. Oxygen analysis of initial trials

\begin{tabular}{|c|c|c|c|}
\hline sample & treatment & Oxygen [wt $\%$ ] & $\pm[\mathrm{wt} \%]$ \\
\hline \multirow{3}{*}{$\begin{array}{c}\text { Powder: } \\
\text { ASC100.29 }\end{array}$} & as delivered & 0.094 & 0.002 \\
\hline & $30 \min 300^{\circ}$ air & 0.222 & 0.008 \\
\hline & $60 \min 300^{\circ}$ air & 0.261 & 0.009 \\
\hline \multirow{3}{*}{ Powder: AstaloyCrM } & as delivered & 0.187 & 0.007 \\
\hline & $30 \min 300^{\circ}$ air & 0.264 & 0.002 \\
\hline & $60 \min 300^{\circ}$ air & 0.280 & 0.008 \\
\hline \multirow{5}{*}{$\mathrm{ASC}+0.5 \mathrm{C} 600 \mathrm{MPa}$} & untreated & 0.172 & 0.014 \\
\hline & $30 \min 300^{\circ}$ air & 0.215 & 0.025 \\
\hline & $60 \min 300^{\circ}$ air & 0.245 & 0.023 \\
\hline & $30 \min 400^{\circ}$ air & 0.251 & 0.047 \\
\hline & $60 \min 400^{\circ}$ air & 0.519 & 0.018 \\
\hline \multirow{5}{*}{$\mathrm{CrM}+0.5 \mathrm{C} 600 \mathrm{MPa}$} & untreated & 0.146 & 0.008 \\
\hline & $30 \min 300^{\circ}$ air & 0.296 & 0.044 \\
\hline & $60 \min 300^{\circ}$ air & 0.290 & 0.007 \\
\hline & $30 \min 400^{\circ}$ air & 0.388 & 0.072 \\
\hline & $60 \min 400^{\circ}$ air & 0.499 & 0.086 \\
\hline
\end{tabular}

Table 1 shows the oxygen analysis for these initial trials. It is easy to see that oxidation at $400^{\circ} \mathrm{C}$ is too severe, thus $300^{\circ} \mathrm{C}$ for $60 \mathrm{~min}$ in the drying chamber was the temperature chosen for the main experiments. As a reference, untreated powder was 
pressed, and the specimens were characterized. Compared to the usual O-contents of the used powders (typically $0.08 \mathrm{wt} \%$ for ASC 100.29 and $0.16 \mathrm{wt} \%$ for AstaloyCrM) the effect of the oxidation is evident. The untreated ASC-sample showed improbable, high oxygen contents, which is obviously caused by the Multical oil used for die wall lubrication. The results show that at $300^{\circ} \mathrm{C}$ the oxidation seems to reach a stable state at 30 min whereas at $400^{\circ} \mathrm{C}$ the effect of soaking time is much stronger. As already shown in [7] the Cr-prealloyed material is not very sensitive to oxidation al low temperatures, since the oxygen levels are comparable to those of plain iron powder, although $\mathrm{CrM}$ is reported to be a very oxygen-sensitive powder. The oxidation of the pressed samples was inhomogeneous (which was intended) and easily can be seen in Fig. 1. Therefore differences between homogeneous (samples pressed of oxidized powders) and inhomogenous samples (oxidized green compacts) can be investigated.

The main experiments were performed with artificial oxidation at $300^{\circ} \mathrm{C}$ in air in a drying chamber. To study the sintering behavior, stepwise sintering was performed at 700 , $800,900,1000,1100,1200$ and $1250^{\circ} \mathrm{C}$ in $\mathrm{N}_{2} / 10 \% \mathrm{H}_{2}(5.0$ purity) for $30 \mathrm{~min}$ in a pusher furnace with gas-tight superalloy tube retort. Additionally, sintering experiments in a dilatometer (Netzsch 402C) coupled with mass spectrometer (MS Netzsch Aeolos, capillary coupling) were performed in pure hydrogen with all 3 sample variants (untreated, artificial oxidized samples and samples fabricated of oxidized powder). Here also full charpy bars were used. The parameters were: $10 \mathrm{~K} / \mathrm{min}$ heating and cooling, $\mathrm{T}_{\max } 1300^{\circ} \mathrm{C}$ held for 60 min, recorded masses: $2\left(\mathrm{H}_{2}\right), 12(\mathrm{C}), 14(\mathrm{~N}), 15\left(\mathrm{CH}_{3}\right), 16\left(\mathrm{CH}_{2}, \mathrm{O}\right), 17(\mathrm{OH}), 18\left(\mathrm{H}_{2} \mathrm{O}\right)$, $28\left(\mathrm{~N}_{2}, \mathrm{CO}\right), 32\left(\mathrm{O}_{2}\right), 44\left(\mathrm{CO}_{2}\right)$.

All mechanical physical and mechanical properties were determined by the samples sintered in the furnace experiments.

\section{RESULTS AND DISCUSSION}

The average green density of Fe- $0.5 \mathrm{C}$ was $6.96 \pm 0.02 \mathrm{~g} / \mathrm{cm}^{3}$ which increased slightly after oxidation treatment to $6.98 \pm 0.02 \mathrm{~g} / \mathrm{cm}^{3}$. The green density of the oxidized and then compacted powder was $6.95 \pm 0.03 \mathrm{~g} / \mathrm{cm}^{3}$. The same trend was observed with Fe-3Cr$0.5 \mathrm{Mo}+0.5 \mathrm{C}$, in which case the reference green density was $6.75 \pm 0.02 \mathrm{~g} / \mathrm{cm}^{3}$, and after oxidation treatment $6.77 \pm 0.02 \mathrm{~g} / \mathrm{cm}^{3}$, whereas the green density of the oxidized powder material was $6.70 \pm 0.03 \mathrm{~g} / \mathrm{cm}^{3}$. This means that the green density is only slightly influenced by the treatment and that the starting point in terms of density changes during sintering is rather the same for all variants - for sure the green density of the prealloyed material is much lower than Fe-0.5C.

The sintered density does not show too pronounced effects of oxidation except for the fact that densification is enhanced especially in the Cr-prealloyed system at high sintering temperatures (Fig. 3). It is well known that the impact energy is a strong indicator for the quality of the sintering process, as indicated by the strength of the sintering contacts. The significant "delay" in the increase of the impact energy with temperature visible for the oxidized Fe- $0.5 \mathrm{C}$ variants compared with the untreated material - the difference being most pronounced at $800^{\circ} \mathrm{C}$-(Fig. 4) is strongly connected to the development of the microstructure which is demonstrated in Fig. 5. Only at $800^{\circ} \mathrm{C}$ sintering temperature there is a significant difference in the microstructure. Whereas the reference material already shows some sintering contacts and carbon dissolution (appearing as pearlite), the oxidized variants look like more or less like green bodies. From $900^{\circ} \mathrm{C}$ on this difference tends to disappear, and the oxidized parts reach comparable impact energies as the reference material or even better ones $\left(1250^{\circ} \mathrm{C}\right)$. The material produced from the oxidized powder shows a very similar behavior, but does not reach the level of the reference material. 


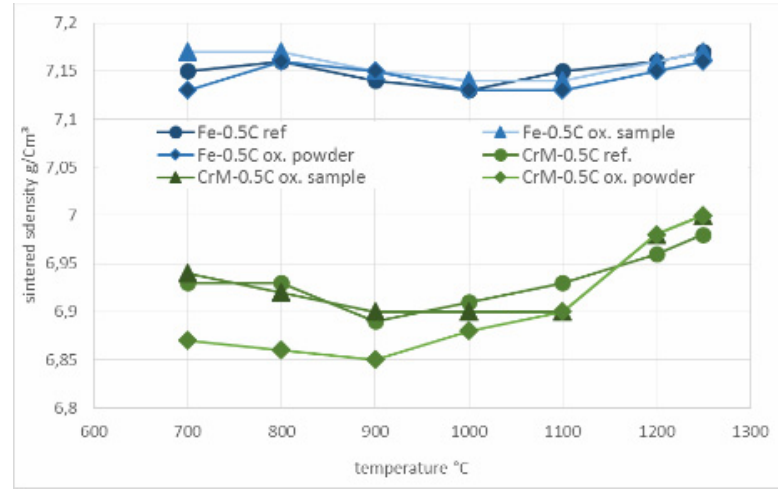

Fig.3. sintered density of differently treated PM-steels sintered $30 \mathrm{~min}$. at varying temperatures in $\mathrm{N}_{2}-10 \% \mathrm{H}_{2}$.

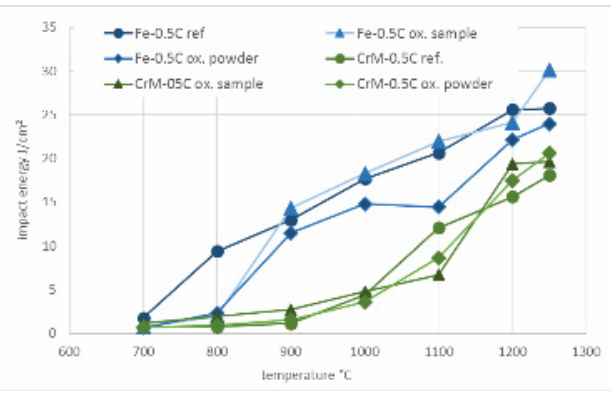

a)

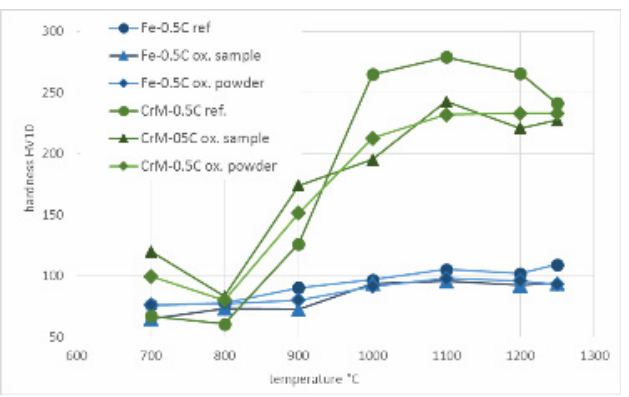

b)

Fig.4. Impact energy (a) and hardness (b) of differently treated PM steels. Sintered 30 min. at varying temperatures in $\mathrm{N}_{2}-10 \% \mathrm{H}_{2}$

The influence of the oxidation seems to be negligible for the Cr-prealloyed material. Although there are marked differences in microstructure development from 700 to $900^{\circ} \mathrm{C}$ the difference in impact energy is negligible (see Fig. 4a). For sure the general impact energies reached at these sintering temperatures are rather low, indicating that the sintering contacts have not been developed very well. This holds also for the reference materials and agrees with the findings described in [8]. The microstructure shows another phenomenon: In contrast to $\mathrm{Fe}-\mathrm{C}$, in the $\mathrm{Cr}$-prealloyed steels the development of the sintering contacts is not linked to carbon dissolution. It can be easily seen that carbon dissolution is strongly dependent on the starting material. Whereas the reference material shows the first dissolution of carbon at $900^{\circ} \mathrm{C}$ the oxidized variants show some pearlite already at $800^{\circ} \mathrm{C}$, also indicated by a strong increase of hardness, although the impact energy and therefore the sintering contacts are not developed very well. In the micrographs, apart from the carbon dissolution also the presence of an oxide layer on the former powder particles is discernible. For this material much higher temperatures are required - at least above $900^{\circ} \mathrm{C}$ - to develop the desired microstructures, as can be seen for sintering temperatures of 1100 and $1200^{\circ} \mathrm{C}$ [8]. This material is a perfect example that hardness by itself is not an indicator for proper sintering, also strength data are required, which means that the ratio of tensile strength to hardness should be in the range of 3.2 as described e.g. by Momeni et al. [10]. 

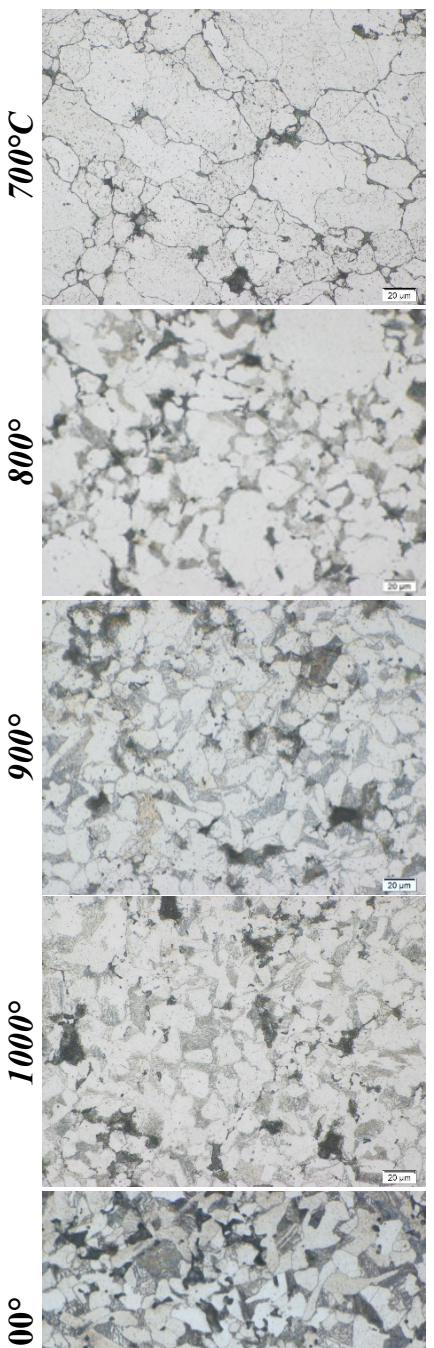

气

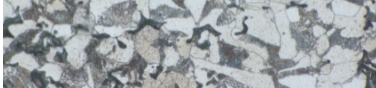

.

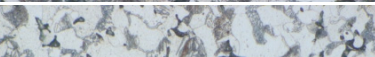

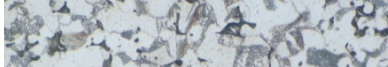

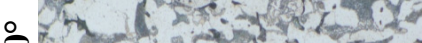

ฮั

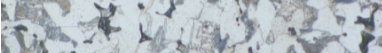
Tis

a) reference
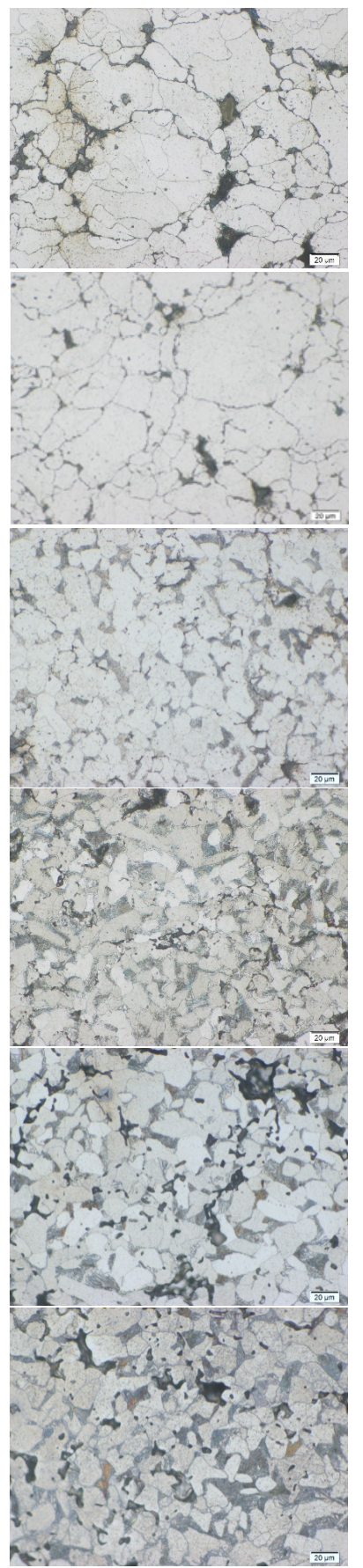

b) oxidized green body
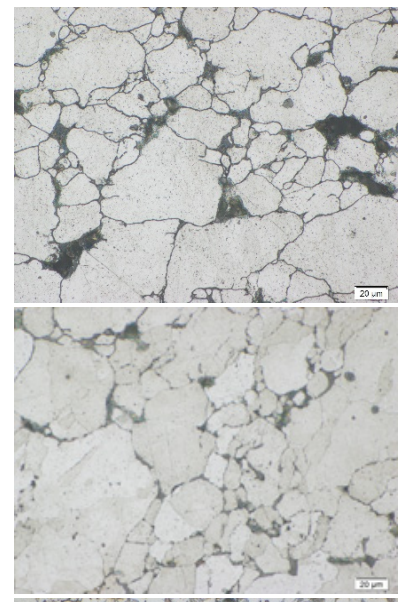

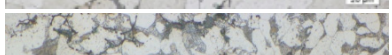

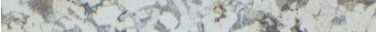

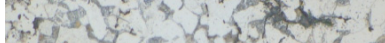

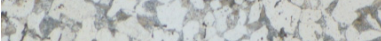

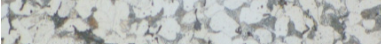

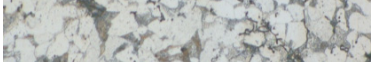

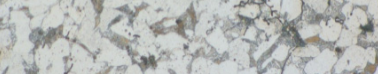
corde 25 is $x=x^{2}+x^{2} x^{2}$

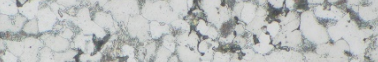

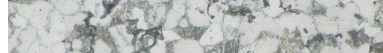

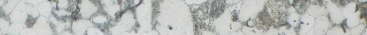

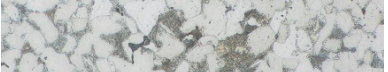

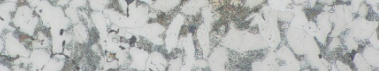

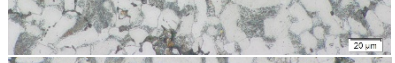

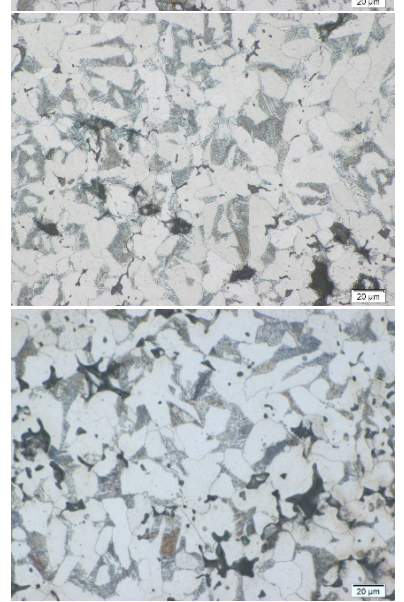

c) oxidized powder

Fig.5. Microstructures of different treated Fe-0.5. Sintered 30 min at $800^{\circ}-1200^{\circ}$ in $\mathrm{N}_{2^{-}}$ $10 \% \mathrm{H}_{2}$. 


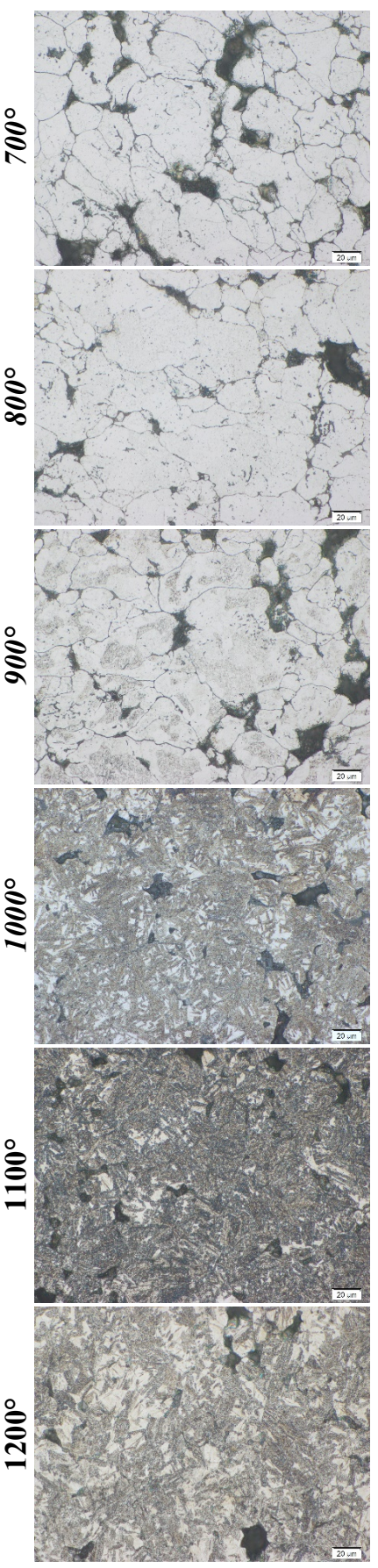

a) reference

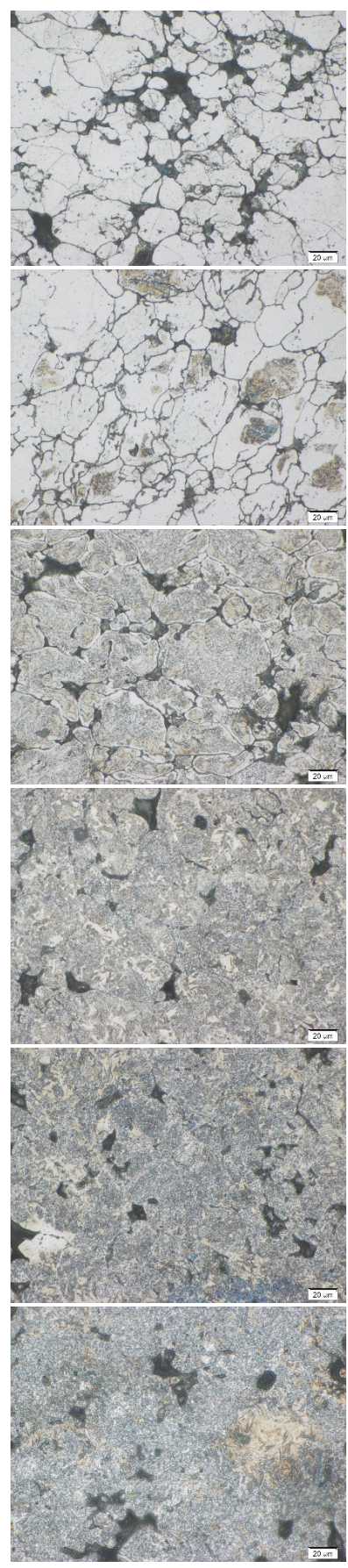

b) oxidized green body

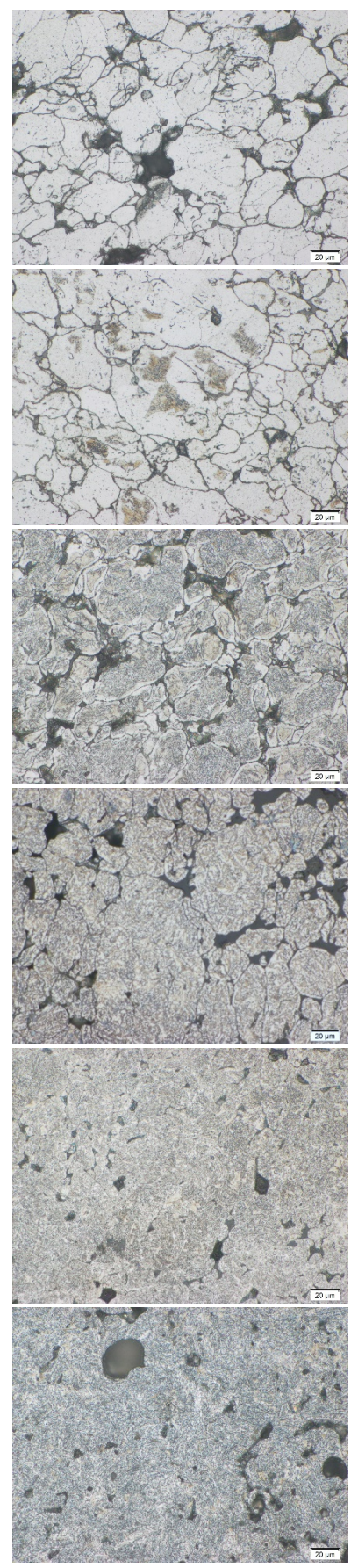

c) oxidized powder

Fig. 6: Microstructures of different treated Fe-3Cr-0.5Mo-0.5C. Sintered $30 \mathrm{~min}$ at $800^{\circ}$ $1200^{\circ} \mathrm{C}$ in $\mathrm{N}_{2}-10 \% \mathrm{H}_{2}$ 
When comparing the hardness development of both materials the difference is evident. The system $\mathrm{Fe}-\mathrm{C}$ shows a more or less linear increase due to pearlite formation and strengthening of the sintering contacts. The $\mathrm{Cr}$-prealloyed material shows much more complex microstructures as already mentioned. Since this material not only transforms to pearlite during cooling but also in part to bainite, the rise in hardness is much stronger. The ratio bainite/pearlite also depends on the overall carbon content which is higher for the reference material at sintering temperatures above $1000^{\circ} \mathrm{C}$ (see Fig. 6) which then again enhances the transformation to bainite.

The trends for the carbon and oxygen contents of the reference materials are as expected (Fig. 7). The reference material at $700^{\circ} \mathrm{C}$ shows the carbon originally added to the powder mix. At $1000^{\circ} \mathrm{C}$ sintering temperature, when significant carbothermal reduction processes occur, the material shows marked carbon loss. The artificially oxidized Fe- $0.5 \mathrm{C}$ specimens, both from oxidized compact and oxidized powder, differ from the reference at and above $900^{\circ} \mathrm{C}$ sintering temperature, showing significantly higher carbon loss due to the necessary reduction processes. It is interesting that the reduction of the artificially oxidized samples needs higher temperatures, which can be observed by the carbon loss, as the reduction is obviously done by carbothermal reduction, and final oxygen content of the material fit very well with the expected results derived from dilatometry experiment of these powders. The sensitivity of the material to the oxidizing treatment can be seen from the oxygen content. Only at the highest sintering temperatures, the usual, expected oxygen content and therefore the desired mechanical properties are attained.

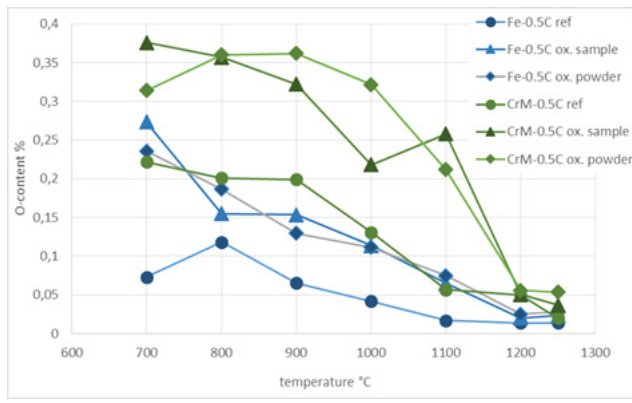

a) carbon content

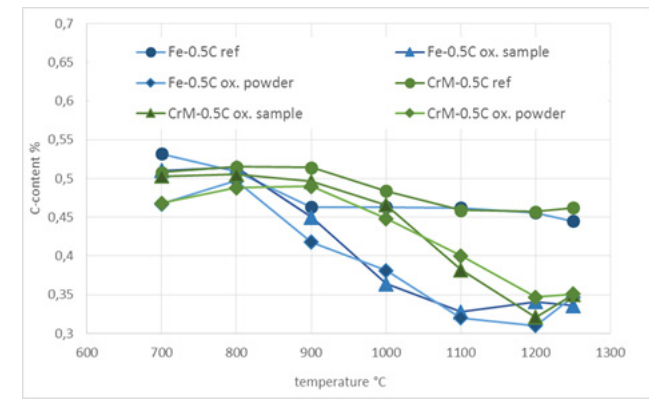

b) oxygen content

Fig.7. Interstitial content of differently treated PM steels. Sintered $30 \mathrm{~min}$. at varying temperatures in $\mathrm{N}_{2}-10 \% \mathrm{H}_{2}$.

Monitoring the sintering experiments by dilatometry coupled with mass spectrometry (MS) showed that although the Cr-material is expected to be more sensitive to oxidation, both materials exhibit very similar behaviour when oxidized at rather low temperatures (Fig.8). The artificial oxidizing of Fe-0.5C material indicates that mainly the surface of the material is oxidized which is revealed by the larger peaks of water $(\mathrm{m} 18)$ in the early (= low temperature) region of the sintering process. When comparing the oxygen content it is clear that even sintering at a temperature of $800^{\circ} \mathrm{C}$ in $\mathrm{N}_{2}-\mathrm{H}_{2}$ is sufficient to significantly reduce the oxygen content. The internal oxides are not affected to the same degree, the peaks of $\mathrm{m} 28$ are only slightly higher compared to the reference material. This little higher consumption of carbon as reducing agent explains the slight difference in oxygen content and final carbon content in the sintered samples. The difference caused by the heating rates, slow heating in the dilatometer experiment and fast heating in the furnace, 
is rather small for the Fe-C system, but there seems also to be a slight "internal getter" effect.

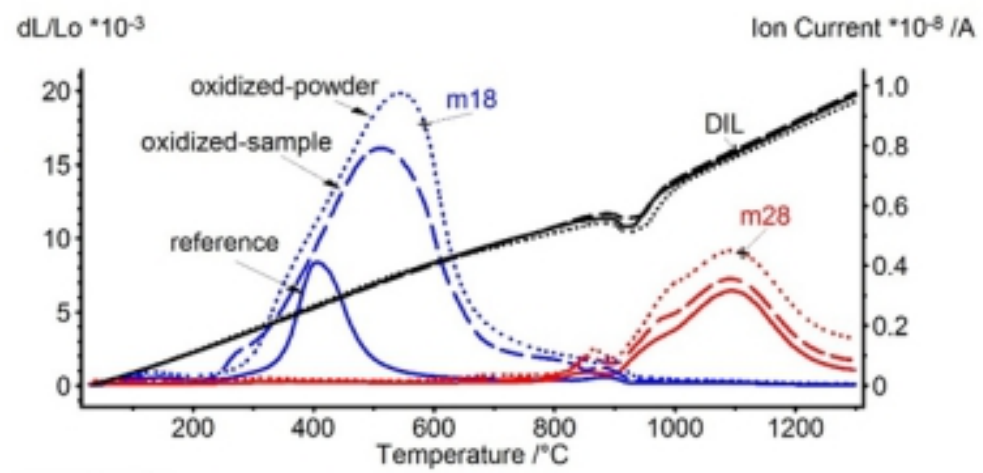

a) $\mathrm{Fe}+0.5 \mathrm{C}$

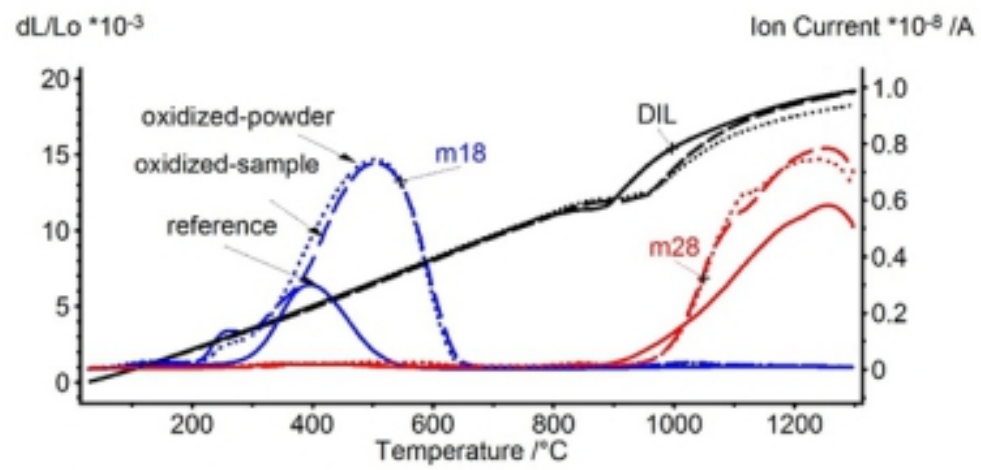

b) $\mathrm{Fe}-3 \mathrm{Cr}-0.5 \mathrm{Mo}+0.5 \mathrm{C}$

Fig.8. DIL-MS vs. temperature of differently treated PM-steels (untreated and oxidized samples, samples produced of oxidized powder, full charpy bars), $10 \mathrm{Kmin}^{-1}$, $60 \mathrm{~min}$ $1300^{\circ} \mathrm{C}$ heating section, plain $\mathrm{H}_{2}$.

For the Cr-steel it is interesting to see that the strongest increase in deoxidation, i.e. the most pronounced reduction peak, is not observed for the more stable oxides but for the surface oxides indicated as iron oxides by their reducibility in $\mathrm{H}_{2}$ at low temperatures, which agrees very well with the findings in [7]. Also here the water peak $(\mathrm{m} 18)$ is much larger compared to the reference material. But here we see significant differences between the pusher furnace experiments and the dilatometer since the heating of the material is done in different ways. Whereas in the dilatometer the samples are heated at constant rate $(10 \mathrm{~K} / \mathrm{min})$, in the experiments in the furnace the boats with the samples are placed in the hot zone of the furnace and are heated up according more or less to the heat capacity of the material. When heated in the furnace, low temperature reduction by $\mathrm{H}_{2}$ is only very limited, and the oxygen transfer of the surface oxides to more stable ones ("internal gettering") can occur whereas this will not happen in the dilatometer since the reduction of the surface oxides by $\mathrm{H}_{2}$ is almost complete in all cases before the transfer becomes possible. It has however to be mentioned that these findings are only valid for treatments at low temperatures. It has been shown in [11] that a heat treatment by heating to $650^{\circ} \mathrm{C}$ without soaking time in inert atmosphere (i.e. without oxidation) changes the surface composition 
of the Cr-prealloyed material in such a way that deoxidation at low temperatures by hydrogen becomes impossible ("internal getter" effect).

\section{CONCLUSIONS}

As expected the artificial oxidizing of the powders and samples increases primarily the amount of oxides on the surface of the powder. Surprisingly the presence of oxygen-sensitive elements like chromium in prealloyed powder does not have a strong impact on oxidation at the temperature chosen here, and the predominant oxides formed are iron oxides. The situation may completely change when the oxidation is done at higher temperatures, allowing an enrichment of $\mathrm{Cr}$ on the former iron oxide surface (e.g. $\left.600^{\circ} \mathrm{C}\right)$.

Stepwise sintering followed by consecutive analysis, combined with dilatometric + MS experiments, proved to be a powerful tool to understand the mechanisms during the sintering of these materials.

Although the initial oxygen contents of plain iron and Cr-alloyed material after artificial oxidation are comparable, the sintering experiments show markedly different behavior for the investigated materials.

For $\mathrm{Fe}-\mathrm{C}$ the development of the mechanical properties and the interstitial content of the sintered material is indicated by the microstructure. The carbon and oxygen contents correspond in principle to the behavior in the dilatometric-MS experiment, although the carbon burn-off during the furnace experiment is an indicator that there is also a slight "internal getter" effect for the system $\mathrm{Fe}-\mathrm{C}$ when heated rather fast. The carbon dissolution and the oxygen removal are slightly retarded for the artificially oxidized material. But if the sintering temperature is high enough the developed microstructures do not show significant differences any more, although the measured $\mathrm{C}$-content is lower for the pre-oxidized materials due to the use of carbon as reducing agent. These small differences cannot be distinguished from the pearlite-ferrite ratio.

The Cr-prealloyed variant behaves differently. Here also the development of the mechanical properties runs in parallel with the microstructural development. But there are distinct differences to the Fe-C system. Here the first carbon dissolution, indicated by the first formation pearlite, is found at lower sintering temperatures in the artificially oxidized materials, although the removal of the surface oxides is not complete. This is different in the furnace sintering where "push-in-push-out" is applied compared to the dilatometric experiment done with constant heating rate. Therefore the high heating rate in the furnace may allow oxygen transfer reactions which are less likely in the dilatometric run. Therefore deoxidation in the furnace is somewhat different to that in the dilatometer, and also the temperature effects on hardness/impact energies are different. Also the sintering temperatures necessary to reach acceptably low oxygen contents are much higher for the artificially oxidized material. This coincides with significantly higher carbon loss and different microstructure compared with the reference material.

\section{REFERENCES}

[1] Chasoglou, D., Hryha, E., Norell, M., Nyborg, L: Applied Surface Science, vol. 268, 2013, p. 496

[2] Nyborg, L., Hryha, E. In: Advances in Powder Metallurgy \& Particulate Materials 2014, Proceedings of the 2014 International Conference on Powder Metallurgy \& Particulate Materials. Orlando, FL, MPIF, Princeton NJ, 2014, Vol. 2, p. 153

[3] Chasoglou, D., Hryha, E., Nyborg, L. In: Proc. Euro PM2009, Copenhagen, Denmark, Oct. 12-14, EPMA, UK 2009, Vol. 2, p. 181

[4] Chasoglou, D., Hryha, E., Nyborg, L. In: Proceedings of World PM2010, Florence, 
EPMA, Shrewsbury UK, 2010, Vol. 2, p. 3

[5] Gierl-Mayer, C., Danninger, H., De Oro, R., Hryha, E. In: Advances in Powder Metallurgy and Part. Materials 2014; Proceedings of World PM Orlando, Florida May 18-22 2015, Eds. R.A. Chernenkoff, W.B. James, p. 05-74

[6] Gierl-Mayer, C., Danninger, H. In: Lecture at: International Conference on Sintering 2014, Dresden; 24.-28.08.2014

[7] Danninger, H., Nikolov, D., Leitner, G., Jaenicke-Rößler, K. In: Proc. Int. Conf. "Sintering '03”, State College PA, 2003

[8] Kremel, S., Danninger, H., Yu, Y.: Powder Metall. Progress, vol. 2, 2002, no. 4, p. 211

[9] Danninger, H., Gierl, C.: Materials Chemistry and Physics, vol. 67, 2001, no. 1-3, p. 49

[10] Momeni, M., Gierl, C., Danninger, H.: Powder Metallurgy Progress, vol. 8, 2008, no. 3, p. 183

[11] Gierl-Mayer, C., Calderon, R., Danninger, H.: JOM, vol. 68, 2016, no. 3, p. 920 